\title{
Metal oxide thin films and nanostructures for self-cleaning applications: current status and future prospects
}

\author{
Mamidipudi Ghanashyam Krishna ${ }^{1, a}$, Madhurima Vinjanampati ${ }^{2}$, and Debarun Dhar Purkayastha ${ }^{3}$ \\ ${ }^{1}$ School of Physics, University of Hyderabad, Hyderabad 500046, India \\ ${ }^{2}$ Department of Physics, Central University of Tamil Nadu, Thiruvarur 610001, India \\ ${ }^{3}$ Department of Physics, Mizoram University, Aizawl 796004, India
}

Received: 24 January 2013 / Accepted: 17 May 2013

Published online: 18 June 2013 - (C) The Author(s) 2013

\begin{abstract}
Surfaces that exhibit reversible wettability toward water are extremely important for a variety of technological applications. In this context, the development of superhydrophobic and superhydrophilic surfaces for self-cleaning applications has been receiving a great deal of attention in the last few years. In this review, an overview of the current state-of-science and technology of self-cleaning surfaces is presented. The current understanding of physics of wetting leading to surfaces with predictive, controllable and reversible wettability is first presented. The review then focuses on materials, mainly metal oxides and their composites, employed for self-cleaning applications. It is shown that, although conventionally oxides and polymers are considered for self-cleaning applications, recent developments point toward the use of artificially engineered surfaces with hierarchical roughness. Applications of self-cleaning films in nonconventional areas such as protection of fabrics, solar cells and structures related to cultural heritage are discussed. The review ends with an outlook for the future in terms of science and technology of self-cleaning surfaces.
\end{abstract}

\section{Introduction}

The wettability of surfaces by fluids has been the subject of great interest for many years since it affects a large number of fields ranging from medicine to electronics. In particular, the wettability of surfaces by water has been investigated in detail. It is well known that there are many natural surfaces such as lotus and rice leaves that have very interesting water-repellent properties. Mimicking the behavior of these surfaces was made difficult due to the absence of any experimental evidence for the origin of the observed contact angles. The first experimental evidence was presented by Barthlott and Neinhuis [1] when they reported images of the surface morphology, leading to an understanding of the origin of the water-repellent nature of the surface of a lotus leaf. Similar observations on numerous other plants and insects [2-9] then led to the development of artificial man-made water-repellent or superhydrophobic surfaces. Based on the contact angle $(C A)$, surfaces are conventionally classified as either hydrophobic $\left(C A>90^{\circ}\right)$ or hydrophilic $\left(C A<90^{\circ}\right)$. There is further classification wherein surfaces with $C A>150^{\circ}$ are called superhydrophobic and those with $C A<10^{\circ}$ are termed as superhydrophilic. The lotus effect refers to the superhydrophobic nature of a surface. The superhydrophobicity of lotus leaves is ascribed to the presence

\footnotetext{
a e-mail: mgksp@uohyd.ernet.in
}

of micro/nanostructured papillae covered by hydrophobic wax crystals on their surfaces which leads to decrease in contact area between the water droplet and lotus leaf [1].

Wetting of a surface is characterized by two distinct states - complete wetting and complete non-wetting. Complete wetting is characterized by a contact angle of $0^{\circ}$ and that of non-wetting by a contact angle that is close to $180^{\circ}$. A surface is said to switch wettability if, by a change in an external parameter such as surface morphology, temperature, the wetting of the surface changes from complete wetting (superhydrophilic) to complete non-wetting (superhydrophobic). All intermediate states of wetting with contact angles between 0 and $180^{\circ}$ are possible. Therefore, an additional feature of interest is the reversible wettability of these surfaces leading to self-cleaning. Self-cleaning surfaces have drawn considerable interest from perspectives of both fundamental research and applications [10]. They find applications in diverse fields from daily life to the industry including self-cleaning exterior construction materials, interior furnishing materials, road construction materials, solar cells, car mirrors, textiles, utensils, roof tiles, etc. [11-15]. Self-cleaning surfaces use sunlight and natural rainfall to clean their surface. As a consequence less manual labor is required which in turn leads to decrease in maintenance costs.

Materials that exhibit superhydrophobicity can be inorganic, organic or hybrids/nanocomposites. Since 
wettability is essentially a surface property, all applications rely on the ability to fabricate thin films or nanostructures with controlled and desired surface morphology. It is important to understand the underpinning science to enable manipulation and engineering of surfaces with predictable wettability behavior and reproducible contact angles.

The main challenges, and therefore opportunities, in further development of this area lie in (1) better quantitative understanding of the science of wetting and self-cleaning, (2) development of new materials and structures with controlled and switchable wettability and (3) development of process technologies that are amenable to scale up, since superhydrophobic surfaces are essentially thin films. A number of recent reviews have focused on various aspects of superhydrophobic and self-cleaning surfaces $[8,9]$. However, recent developments in the theories and models of self-cleaning were not discussed extensively. In addition, use of periodic nanostructures for self-cleaning applications as well as the state of art in oxide coatings on flexible or fabric-type superhydrophobic surfaces have been discussed in a very limited fashion.

The current review, hence, presents an overview of the various theories and models that are available, currently, to design superhydrophobic self-cleaning surfaces. The status of metal oxides, polymeric film and polymermetal oxide nanocomposite materials used in these applications and the different processing techniques with respective advantages and disadvantages are outlined. The importance of self-cleaning coatings and nanoparticles embedded in fabrics, tiles, solar cells and for protection of heritage structures is presented. The review ends with the authors' perspective on the outlook for future work on self-cleaning surfaces.

\section{Theory}

In general, there are two routes to create self-cleaning surfaces (1) superhydrophilic-triggered self-cleaning surfaces, (2) superhydrophobic-triggered self-cleaning surfaces. The flowchart for creating self-cleaning surfaces is shown in Figure 1.

The most common method to quantify hydrophilicity and hydrophobicity of a surface is through measurement of contact angle. The wetting is characterized by the contact angle $\theta$ of liquids over the solid surfaces. The contact angle is often used as a fast and easy technique to gain qualitative information about the chemical nature of the surface. The primary equation that quantified contact angle of a liquid droplet on a flat surface was given by Young [16]. Contact angle can be related to the three interfacial tensions via Young's equation:

$$
\cos \theta=\frac{\gamma_{\mathrm{SV}}-\gamma_{\mathrm{SL}}}{\gamma_{\mathrm{LV}}}
$$

where $\gamma_{\mathrm{SV}}=$ solid-vapor interfacial tension, $\gamma_{\mathrm{SL}}=$ solidliquid interfacial tension, $\gamma_{\mathrm{LV}}=$ liquid-vapor interfacial tension.
Wettability is characterized by not only the chemical composition but also the roughness of the surface. Young's equation is developed for the case of an ideal solid surface, which is defined as a smooth, rigid, chemically homogeneous, insoluble and a non-reactive surface. Wetting on rough surfaces of solid cannot be described by Young's equation and wetting models that correlate surface roughness with the equilibrium contact angle are Wenzel [17] and Cassie-Baxter [18] models. The Wenzel apprarentcontact angle can be related to true contact angle by the relation:

$$
\cos \theta_{\mathrm{W}}=r_{\mathrm{W}}\left[\frac{\gamma_{\mathrm{SV}}-\gamma_{\mathrm{SL}}}{\gamma_{\mathrm{LV}}}\right]=r_{\mathrm{W}} \cos \theta_{\mathrm{Y}}
$$

where $r_{\mathrm{W}}$ is the Wenzel's roughness factor and may be defined as the ratio of the actual area of a rough surface to the geometric projected area. The Cassie-Baxter's equation describes the wetting regime when air is trapped in the microstructures of the surface, and liquid sits on top of asperities. As a result of intrusion of air in the rough structure, a water molecule is not able to displace the air. The apparent-contact angle $\left(\theta_{\mathrm{CB}}\right)$ in this case is given by the Cassie-Baxter's equation which is

$$
\cos \theta_{\mathrm{CB}}=\left(r_{\mathrm{f}} f \cos \theta_{\mathrm{Y}}+f-1\right),
$$

where $\theta_{\mathrm{Y}}$ is the Young contact angle, $f$ is the fraction of the projected area of the solid surface that is wetted by the liquid and $r_{\mathrm{f}}$ is the roughness ratio of the wetted area. The pictorial representations of Wenzel and Cassie-Baxter equations are given in Figure 2.

In Wenzel's model, the liquid droplet keeps contact with the solid surface at all points whereas in Cassie state the liquid sits only across surface protrusions, thus resulting in a droplet suspended on a composite solid and vapor phase. In general, Wenzel's model deals with the homogeneous surfaces whereas Cassie-Baxter's model was found to be functional for heterogeneous surfaces. These models have been used, traditionally, to explain all wettability behavior.

The Wenzel and Cassie-Baxter models are useful to explain observed wetting behavior in most cases. However, these models do not rigorously account for some parameters that are important in applications. An example of such a parameter is contact angle hysteresis $(\mathrm{CAH})$. $\mathrm{CAH}$ is the difference between the advancing and receding CAs. Two different types of CAH effects are generally observed. The first one is the so-called "petal effect" which means the surface has high $C A$, large $\mathrm{CAH}$ and strong adhesion to water. The opposite effect exhibited by the lotus leaf leads to high $C A$, small $\mathrm{CAH}$ hysteresis and low adhesion to water. The difference between the advancing and receding angles $\theta_{\mathrm{adv}}$ and $\theta_{\text {rec }}$ can be written as [19]:

$$
\theta_{\mathrm{adv}}-\theta_{\mathrm{rec}}=\left(\frac{8 U}{\gamma R_{o}}\right)^{1 / 2} h(\theta),
$$

where $R_{o}$ is the initial radius of the spherical drop before deposition on the surface, $U$ is the potential barrier to 


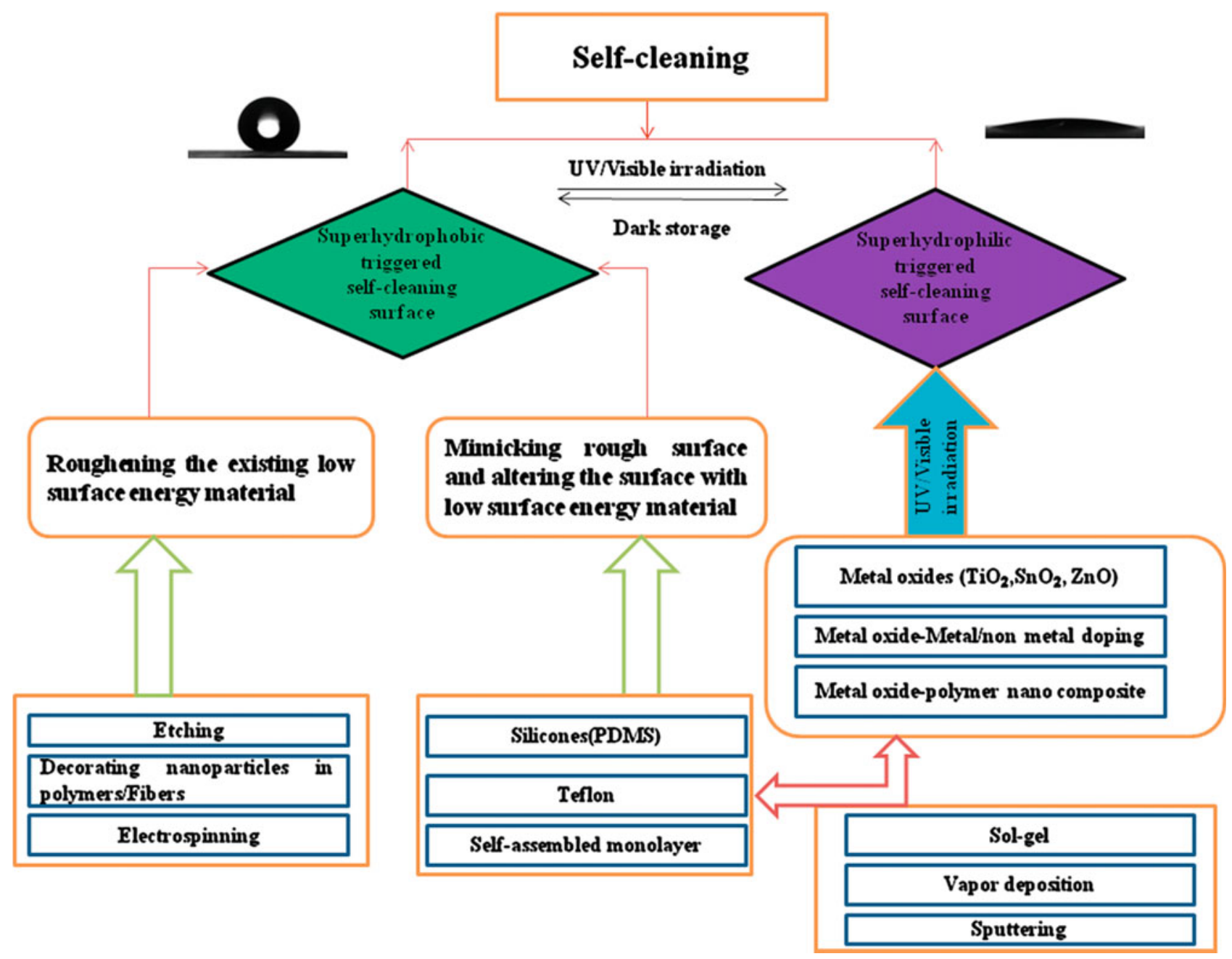

Fig. 1. Schematic illustration of self-cleaning surfaces prepared by different methods.
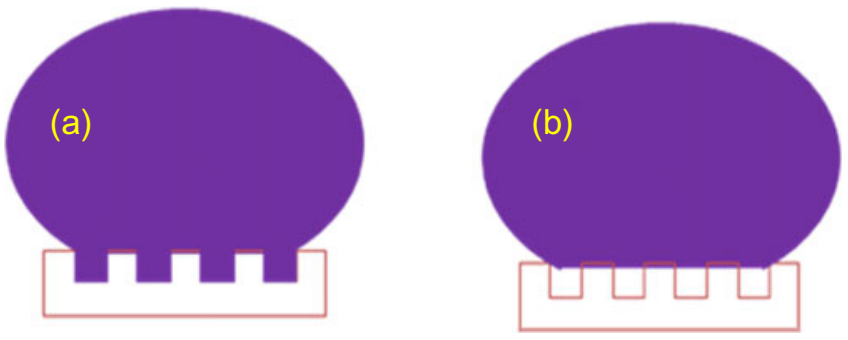

Fig. 2. Diagrammatic representation of (a) Wenzel and (b) Cassie-Baxter state of wetting.

be surpassed by the droplet under its displacement, $\gamma$ is the surface tension and $(h \theta)$ is a geometrical factor of the contact angle hysteresis. The cosines of the advancing and receding angles $\theta_{\mathrm{adv}}$ and $\theta_{\mathrm{rec}}$, respectively, are related to the difference between those angles for a nominally smooth surface, as [20]:

$$
\begin{aligned}
\cos \theta_{\mathrm{adv}}-\cos \theta_{\mathrm{rec}}= & r_{W}\left(1-f_{\mathrm{LA}}\right) \\
& \times\left(\cos \theta_{\mathrm{adv} 0}-\cos \theta_{\mathrm{rec} 0}\right)+H_{\mathrm{t}} .
\end{aligned}
$$

The first term on the right-hand side of the equation corresponds to the inherent $\mathrm{CAH}$ of a smooth surface and is proportional to the fraction of the solid-liquid contact area $\left(1-f_{\mathrm{LA}}\right)$ and $r_{\mathrm{W}}$ is the roughness factor defined earlier. The second term $\mathrm{H}_{\mathrm{t}}$ accounts for the effect of surface roughness on $\mathrm{CAH}$. A further extension of this treatment to include surfaces with hierarchical roughness leading to a composite interface which is intermediate to the CassieWenzel states shows that the energy barrier that needs to be surmounted is dependent on the dimensions of the structure. For example for a surface consisting of pillars of height a with interpillar separation of $b$ as shown in Figure 3 , the energy barrier, $E_{\text {trans }}$, for the wetting transition to occur is given by [19]:

$$
E_{\mathrm{trans}}=\frac{2 \pi R^{2} a\left(\gamma_{\mathrm{SL}}-\gamma_{\mathrm{SA}}\right)}{b}=\frac{-2 \pi R^{2} a \gamma \cos \theta}{b}
$$

where $R$ is the radius of the contact area and $\gamma$ is the surface tension. If $\mathrm{W}$ is the pillar width then the roughness factor and contact areas can be expressed as $r=1+4 R /(\mathrm{W} / a)$ and $R=1 /(b / a+1)^{2}[21]$.

These equations lead to the conclusion that a composite interface consisting of a hierarchical roughness (such as a periodic structure of micro/nanopillars) is ideal for 


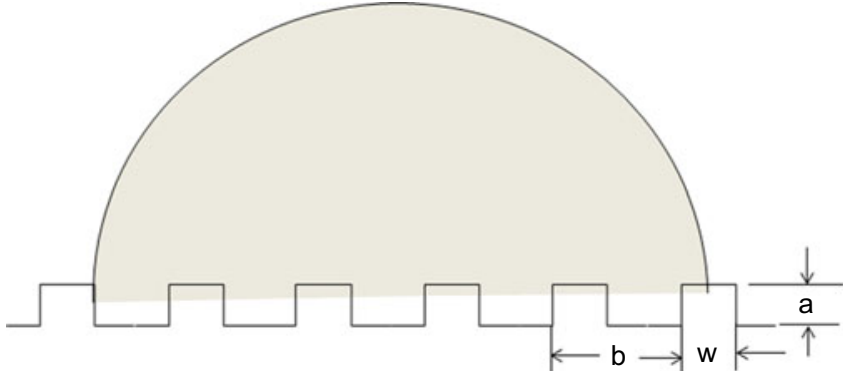

Fig. 3. Schematic diagram of the wetting of a composite interface consisting of micro/nanopillars.

self-cleaning applications and can be used as the basis for the design of surfaces with controllable wettability.

\section{Superhydrophobicity- and superhydrophilicity-triggered self-cleaning surfaces}

\subsection{Superhydrophobicity-triggered self-cleaning surfaces}

Superhydrophobicity results when the normal hydrophobicity of a smooth substrate is amplified by roughness. As stated in the Introduction, superhydrophobic surfaces show extreme water repellence having a $C A>150^{\circ}$. In addition, for practical applications, the surfaces should also exhibit low contact angle hysteresis along with selfcleaning properties [19-21]. The schematic representation of a water droplet over smooth, microstructure, nanostructure and hierarchical structure is shown in Figure 4. It is evident that the superhydrophobicity is due to the hierarchical roughness of the substrate. The motion of droplet over smooth and self-cleaning superhydrophobic surfaces is illustrated in Figure 5.

Apart from lotus leaf, rose petal, several plant leaves, insect wings, water strider legs, Namib Desert beetle show superhydrophobic behavior. Studies on several natural hydrophobic surfaces have shown that they exhibit hierarchical (micro/nanostructure) roughness [1-7,22-24]. Different superhydrophobic surfaces from nature and their microstructure through SEM images are shown in Figure 6. An overview of biological surfaces exhibiting superhydrophobic behavior is available in the literature [9].

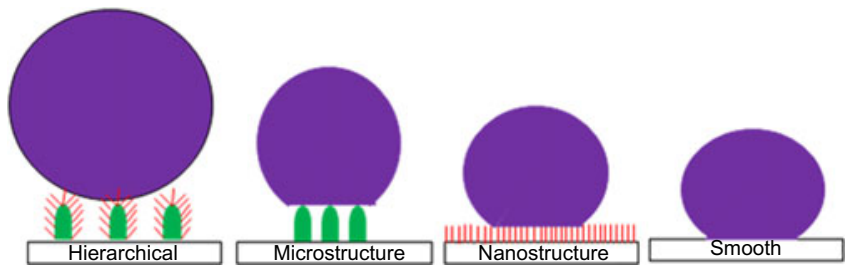

Fig. 4. Water droplet over smooth, nano, micro and hierarchical roughness.

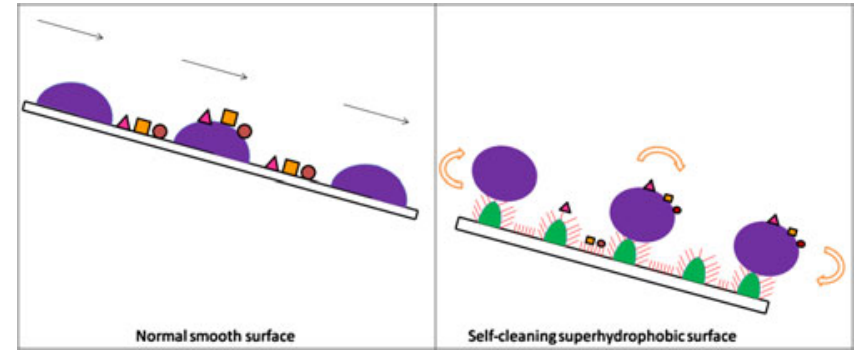

Fig. 5. Schematic representation of motion of water droplet over smooth and self-cleaning superhydrophobic surface.
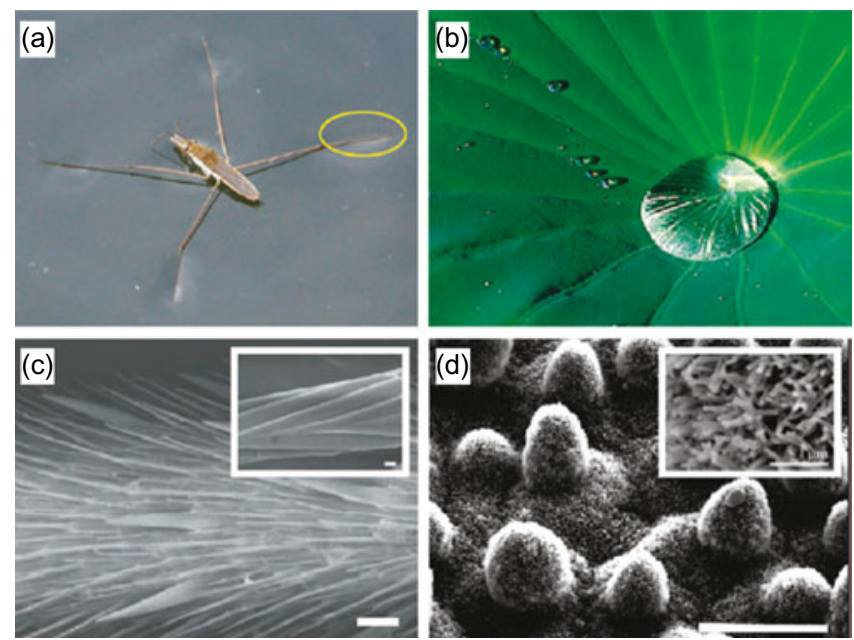

Fig. 6. Hierarchical surface structures of biological waterrepellent surfaces from nature. (a) A water strider (Gerris remigis) standing on a water surface, (b) lotus leaves (Nelumbo nucifera) on which water droplets are freely moving, (c) the two-level hierarchical structure of a water strider's leg and (d) the hierarchical structure of lotus leaves (reproduced with permission of Ref. [5]).

\subsection{Superhydrophilic-triggered self-cleaning surfaces}

Superhydrophilic surfaces are characterized by water contact angles $<10^{\circ}$. Water spreads and completely wets such surfaces and carries away any dirt on them. For example, in the presence of sunlight, organic pollutants that are present on the surface as impurity are chemically broken and hydrophilicity results in washing away the contaminants from the surface. In the following sections the materials used, methods of processing and applications of superhydrophilic surfaces are reviewed.

\subsection{Self-cleaning action of metal oxides}

The self-cleaning mechanism of metal oxide thin films is based on photocatalytic and photo-induced hydrophilicity of the film due to structural changes of the surfaces. The main reason for the extensive study of wetting properties of metal oxides is that their wettability is generally reversible under UV irradiation and dark storage. Although, the most popular metal oxides that exhibit photocatalytic 
activities are $\mathrm{TiO}_{2}, \mathrm{ZnO}, \mathrm{SnO}_{2}$, other oxides like $\mathrm{SrTiO}_{3}$, $\mathrm{WO}_{3}$ and $\mathrm{V}_{2} \mathrm{O}_{5}$ [25-31] have also been investigated for self-cleaning applications.

Among these oxides, the main center of attention of study in self-cleaning applications has been $\mathrm{TiO}_{2}$ because its oxidizing ability is the strongest [12]. $\mathrm{TiO}_{2}$ is considered to be the ideal choice for self-cleaning applications also due to its photocatalytic and photoinduced hydrophilic properties and good transparency in the visible range of the electromagnetic spectrum. The synergy of photocatalysis and superhydrophilicity is the basis of sustaining self-cleaning ability of metal oxides. Photocatalytic activity degrades organic and inorganic contaminants under ultraviolet (UV) light. In contrast, photoinduced hydrophilicity reduces the water contact angle and thus removes the contaminant from the surface by rain water [32]. Although the mechanism is described in detail only with reference to $\mathrm{TiO}_{2}$ below, it is similar for all other metal oxides used in self-cleaning applications.

Upon UV irradiation, $\mathrm{TiO}_{2}$ mainly absorbs UV photons leading to the generation of electrons and holes on the surface of the film. A photon having energy equal to or higher than that of the band gap moves an electron from the valence band to the conduction band leaving behind a hole in the valence band. The photogenerated electrons and holes either recombine or migrate to the surface to react with contaminant adsorbed on the surface. The hole in the valence band $(\mathrm{VB})$ reacts with $\mathrm{H}_{2} \mathrm{O}$ adsorbed on the surface to produce hydroxyl radicals, and the electron in the conduction band $(\mathrm{CB})$ reduces $\mathrm{O}_{2}$ to produce superoxide ions $\left(\mathrm{O}_{2}^{-}\right)$. Hydroxyl radicals and superoxide ions are particularly reactive to decompose organic compounds present on the $\mathrm{TiO}_{2}$ surfaces because of their strong oxidation power. In photo-induced hydrophilicity some of the holes interact with lattice oxygen creating oxygen ion vacancies and the electrons interact with the metal producing surface trapped electron sites. As a consequence, the binding energy between metal and oxygen atom decreases. The creation of oxygen ion vacancies makes the surface suitable for hydroxyl absorption and as a result these substrates become hydrophilic after UV exposure. An additional advantage of the metal oxide surfaces is the reversible wettability that they exhibit upon storing in the dark and re-exposure to UV radiation [32]. The schematic representation of photocatalytic and photoinduced hydrophilicity, in the case of $\mathrm{TiO}_{2}$ films under UV irradiation, are shown in Figures 7 and 8 respectively.

The superhydrophilic-to-hydrophobic reconversion is due to the replacement of the adsorbed hydroxyl groups by oxygen, which returns the surface geometric and electronic structures similar to the native metal-oxide surfaces. Oxygen bridging sites also play an important role in the surface wettability conversions. $\mathrm{TiO}_{2}$ films under UV irradiation form a metastable state which recovers quickly after UV irradiation is removed. However, hydrophilicity of $\mathrm{TiO}_{2}$ films depends upon the relative humidity and oxygen content in the environment [33]. After the discovery of photoinduced hydrophilicity of $\mathrm{TiO}_{2}$ photocatalyst under UV irradiation, the application of $\mathrm{TiO}_{2}$ as a self-cleaning material has enlarged in the industry. The mechanism

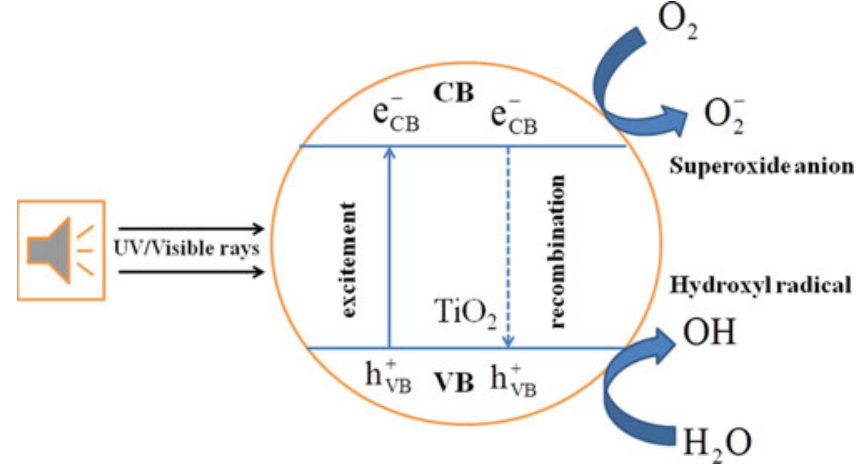

Fig. 7. The photocatalytic activity of $\mathrm{TiO}_{2}$ under UV irradiation.

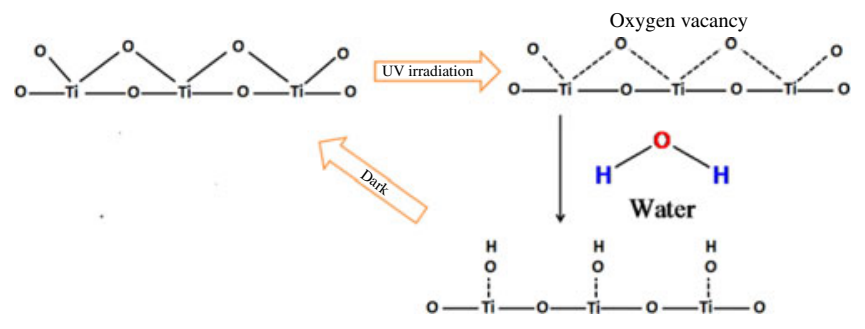

Fig. 8. The photoinduced hydrophilicity of $\mathrm{TiO}_{2}$ under UV irradiation.

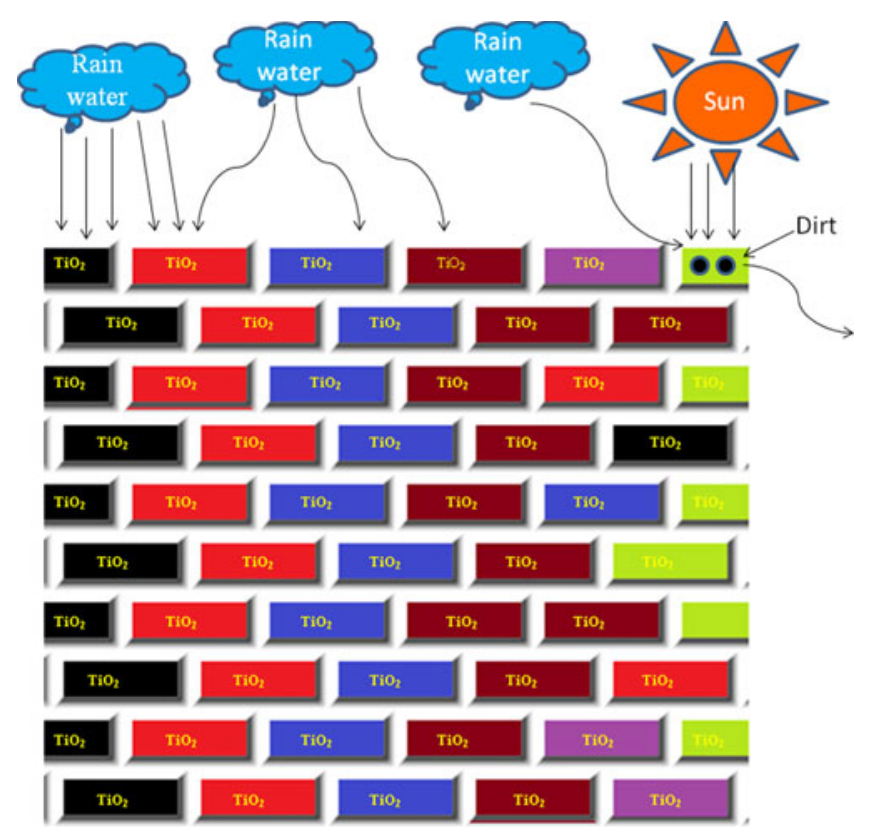

Fig. 9. Self-cleaning action of $\mathrm{TiO}_{2}$ exterior tiles.

of self-cleaning action of $\mathrm{TiO}_{2}$ exterior tiles is shown in Figure 9.

The other well-studied material is $\mathrm{ZnO}$ in which the mechanism of photocatalytic activity is similar to that of $\mathrm{TiO}_{2}$. As in the case of $\mathrm{TiO}_{2}$, the $\mathrm{ZnO}$ surface becomes energetically unstable after the hydroxyl adsorption. Oxygen adsorption is thermodynamically favored and it is more strongly bonded on the defect sites than the hydroxyl 
group. According to the above-described mechanism, the induced superhydrophilic state in $\mathrm{ZnO}$ is unstable with time and may return to the initial hydrophobic state after a while. Consequently, the hydroxyl groups adsorbed on the defective sites can be replaced gradually by oxygen atoms when the UV irradiated films are placed in the dark [34-38]. The typical mechanism of photocatalysis in $\mathrm{ZnO}$ is shown below.

$$
\begin{aligned}
& \mathrm{ZnO}+2 h \nu \rightarrow 2 h^{+}+2 e^{-} \\
& \mathrm{O}^{2-}+h^{+} \rightarrow \mathrm{O}_{1}^{-}(\text {surface trapped hole }) \\
& \mathrm{O}_{1}^{-}+h^{+} \rightarrow \frac{1}{2} \mathrm{O}_{2}+(\text { oxygen vacancy })
\end{aligned}
$$

\subsection{Self-cleaning action of metal oxide with metal and non-metal doping}

It is well known that the fraction of UV photons in solar light is very small (approximately $5 \%$ ), and artificial light sources inside the room emit mainly visible photons. For a photocatalyst to be useful in normal sunlight it is, thus, needed to alter the properties so that lower energy photons can be absorbed and initiate the self-cleaning process. Hence, to transform a UV-light-responsive surface into a visible-light responsive surface, a variety of synthetic schemes have been proposed. In order to obtain materials with improved photocatalytic property, metal and nonmetal doping has been performed. Metal doping acts as a stimulator of self-cleaning properties under visible-light irradiation. Doping of metal ions such as $\mathrm{Cr}, \mathrm{V}, \mathrm{Fe}, \mathrm{Pb}, \mathrm{Cu}$ has been explored [39-41], but it should be noted that improvement has not been observed in all cases. Non-metal doped $\mathrm{TiO}_{2}\left(\mathrm{C}-\mathrm{N}-\mathrm{F}\right.$ doped $\left.\mathrm{TiO}_{2}\right)$ thin films are also active under visible-light irradiation and can therefore act as self-cleaning surfaces [42-44]. It is generally observed that non-metal doping is more promising than metal doping to produce visible-light photocatalytic activity. One of the serious concerns in this work is that after doping with non-metal ion, although it becomes active under visiblelight irradiation, the activity is not as pronounced as in the case of UV light. Another approach is to make metal oxide-metal nanocomposites [45]. The driving mechanism in these cases is the decrease in band gap due to doping leading to higher fraction of visible photons being absorbed. However, it is also found that there is a trade-off between tailoring band gap and decreased photocatalytic behavior of the film. It can be stated that doped metal oxides hold promise for tuning the photocatalytic activity of oxides.

\subsection{Self-cleaning action of metal oxide/metal oxide nanocomposite}

There are a number of applications in which the selfcleaning surface is required to have low reflectance in the desired region of the spectrum. One of the approaches to achieve this is to make either metal oxide/metal oxide nanocomposites or multilayers of metal oxides. Multilayered oxides are well known for their antireflection properties. The doping of one oxide with another metal oxide can produce low-energy states that trap electron-hole charge carriers and thus prevent charge recombination resulting in enhancement of photocatalytic activity. For example, it was observed that addition of $\mathrm{SiO}_{2}$ to a $\mathrm{TiO}_{2}$ film improved the hydrophilic properties, and hydrophilic state is persistent for a prolonged period of time in the absence of UV light $[46,47]$. This behavior can be controlled by varying the $\mathrm{SiO}_{2}$ concentration, which is not possible in pure $\mathrm{TiO}_{2}$ films.

\subsection{Self-cleaning action of metal oxide coated or embedded textiles}

Self-cleaning action in the textile industry can be obtained by either incorporating nanoparticles or thin film of a photocatalytic metal oxide with self-cleaning properties in the textile $[48,49]$. Anchoring of metal oxide on cotton textile was done by functionalization of metal oxide by negatively charged functional groups. Among photocatalysts, $\mathrm{TiO}_{2}$ and $\mathrm{ZnO}$ have been used extensively in the textile industry because of their potential efficiency in removing undesirable stains, adhered superficial dirt and harmful microorganism through photocatalytic activity. The conventional fibers and polymers are not able to resist adhesion of microorganisms on their surface. Due to the antimicrobial property the molecules of dirt can be broken down by the oxides which prevent any growth of microorganisms on the surface of fabrics or wools and hence properties can be improved. It is also shown that the presence of $\mathrm{TiO}_{2}$ layers on the surface of fabrics augmented the stability of fabric under the influence of UV irradiation. These investigations are in their infancy but are extremely important for the development of water-repellent fabric surfaces. The main challenges relate to the compatibility of processing conditions between the fabric and the oxide nanoparticles or films. It is extremely important that processing techniques that do not rely on harsh conditions such as high temperatures or gas environments are developed. Sol-gel, spray pyrolysis, electrospinning, self-assembly, hydrothermal methods are a few common techniques known to incorporate metal oxide in fabrics, fibers, wools, etc. [50,51]. Among these techniques, electrospinning is a simple, costeffective method that provides a porous film with controlled fiber size. Decoration of polystyrene and polyvinyl chloride fibers, produced by electrospinning, with $\mathrm{TiO}_{2}$ nanoparticles; solar light photocatalytic activity of cotton textile fiber coated with $\mathrm{Au} / \mathrm{TiO}_{2}$ films; and functionalization of silk with $\mathrm{TiO}_{2}$ or $\mathrm{TiO}_{2} / \mathrm{Ag}$ nanoparticles through chemical bonding as an effective way of making self-cleaning silk that also leads to higher stability of silk surface under UV irradiation have shown promise. Water absorption in wool is significantly affected by the presence of nano $\mathrm{TiO}_{2}$ on it and photocatalytic decomposition of methylene blue is pronounced due to the $\mathrm{TiO}_{2}$ embedded in the wool. Other systems include $\mathrm{TiO}_{2} / \mathrm{SiO}_{2}$ composite film over cotton fabrics, silicon modified $\mathrm{TiO}_{2}$ 
M. Ghanashyam Krishna et al.: Metal oxide thin films and nanostructures for self-cleaning applications

coated wool fibers, aluminum oxide on non-woven and woven fabrics and low temperature processed $\mathrm{ZnO}$ nanorod arrays [50-58]. Apart from $\mathrm{TiO}_{2}$, there is work reported on the use of other oxides such as $\mathrm{Al}_{2} \mathrm{O}_{3}, \mathrm{ZnO}$ and some nanocomposites [59-64]. This indicates that there is a great deal of interest in self-cleaning fabrics. However, issues like the mechanical strength of the host fibers in the presence of oxide nanoparticles or layers on the surfaces, processing temperatures, environmental stability have to be resolved.

\subsection{Self-cleaning action of metal oxide in solar cells and protection of architectural heritage}

A recent interest in self-cleaning surfaces has been in the protection of solar cells from airborne dust or particles in remote places like deserts. Dust and other contaminants present on the surface of the solar cell adversely affect the efficiency of a solar power system due to their long-term exposure to harsh environments. A common strategy is to prepare a composite of $\mathrm{TiO}_{2}$ with a low refractive index material such as $\mathrm{SiO}_{2}$, to decrease the refractive index of the resultant film [65] so that the films act both as an antireflection and self-cleaning surface. However, the addition of porosity of the film has some detrimental effect in terms of durability of the coating during the operation [66]. This is an emerging area and it needs further investigation since the presence of such coatings could also affect the efficiency of the cell.

Self-cleaning environment friendly $\mathrm{TiO}_{2}$ coatings are efficient to protect our historical monuments or modern buildings exposed to urban pollution. Clay roofing tiles, due to their prolonged uses, suffer degradation that leads to deterioration of the building. $\mathrm{TiO}_{2}$-based self-cleaning tiles are able to prevent the corrosion in building material. Despite its broad use in the construction industry, there are only few studies available in the field of cultural heritage. Recent studies have shown that $\mathrm{TiO}_{2}$ coated travertine (a porous natural limestone commonly used in monumental building material) acts as a self-cleaning surface due to photocatalytic activity of $\mathrm{TiO}_{2}$. It was also demonstrated that $\mathrm{TiO}_{2}$ can be used in the field of protection, conservation and maintenance of architectural heritage $[67,68]$. Roof tiles coated with $\mathrm{TiO}_{2}$ show photocatalytic activity in the decomposition of methylene blue along with high hydrophilicity and antimicrobial activity [69].

\subsection{Metal oxide-polymer nanocomposite films}

Another important class of self-cleaning materials are metal oxide based polymeric films. Metal oxide-polymer nanocomposites have drawn immense attention due to their potential efficiency in tailoring self-cleaning surfaces [70]. Nakata et al. [71] have prepared $\mathrm{TiO}_{2}-\mathrm{PDMS}$ nanocomposite material that exhibits rewritable wettability transition stimulated by UV irradiation and thermal treatment. It has also been reported that incorporation of silica micro or nanoparticles in a polyurethane matrix may lead to superhydrophobic character [72]. These composite materials were prepared by mixing nanoparticles in different concentration with polymer solutions and then deposited on smooth surfaces. Hou and Wang [73] prepared superhydrophobic polystyrene/titania nanocomposites with superhydrophilic property under UV irradiation. It is postulated that for a particular combination of metal oxide-polymer film, the superhydrophobicity of the composite material is independent of type of the metal oxide used and substrate properties [74]. Sometimes during the photocatalytic process of $\mathrm{TiO}_{2}$, the polymer matrix is degraded. So, in those cases a protective layer between polymer and $\mathrm{TiO}_{2}$ surfaces is essential. Another approach is to use a multilayer film consisting of $\mathrm{TiO}_{2}$ and polyurethane, which not only serves as protective layer but is also able to bind the $\mathrm{TiO}_{2}$ particles onto the coating surface [75].

\section{9 “Designer" superhydrophobic surfaces}

In practice, it is accepted that the hierarchical structures can improve the water repellence $[76,77]$ and as a consequence, preparation of nanostructured surfaces with dual scale roughness is of increasing interest [78]. Based on equations (4)-(6) artificially designed nanostructures consisting of nano/micropillars with varying heights, widths and spacings have demonstrated extreme water repellence of etched inorganic and polymer surfaces [79]. These surfaces have been realized using very elaborate lithographic techniques. Park et al. [80] have investigated the superhydrophobicity of $2 \mathrm{D} \quad \mathrm{SiO}_{2}$ hierarchical micro/ nanorod structures fabricated using a two-step micro/ nanosphere lithography. There are also reports that the patterned and aligned carbon nanotube structures are superhydropobic [81].

There are two ways of designing superhydrophobic surfaces. One way is roughening an existing low surface energy material and another way is through chemical modification of the surface by introducing hydrophobic chemical groups on a rough substrate. Within this framework, several methods have been proposed to mimic superhydrophobic surfaces artificially. Some elegant methods are lithography, etching, self-assembly, electrospinning, layer-by-layer technique, hydrothermal method, sol-gel, chemical vapor deposition, colloidal assembly and other methods. Surface topography plays a major role in the hydrophobic behavior of the surfaces. Techniques such as lithography, etching are effective to fabricate surfaces with different topology such as square pillars, parallel grooves [82-92]. Typical examples of polymer base superhydrophobic surfaces are shown in Figure 10.

More recently, controlled growth of nanostructures such as nanotubes, nanowires, nanorods, nanoflowers, nanoneedles leading to superhydrophobic behavior has also been demonstrated as displayed in Figure 10 [93-98]. Nanostructured $\mathrm{ZnO}, \mathrm{TiO}_{2}$, etched silicon have been used largely to create superhydrophobic surfaces because of their diverse applications. Superhydrophobic $\mathrm{ZnO}$ 

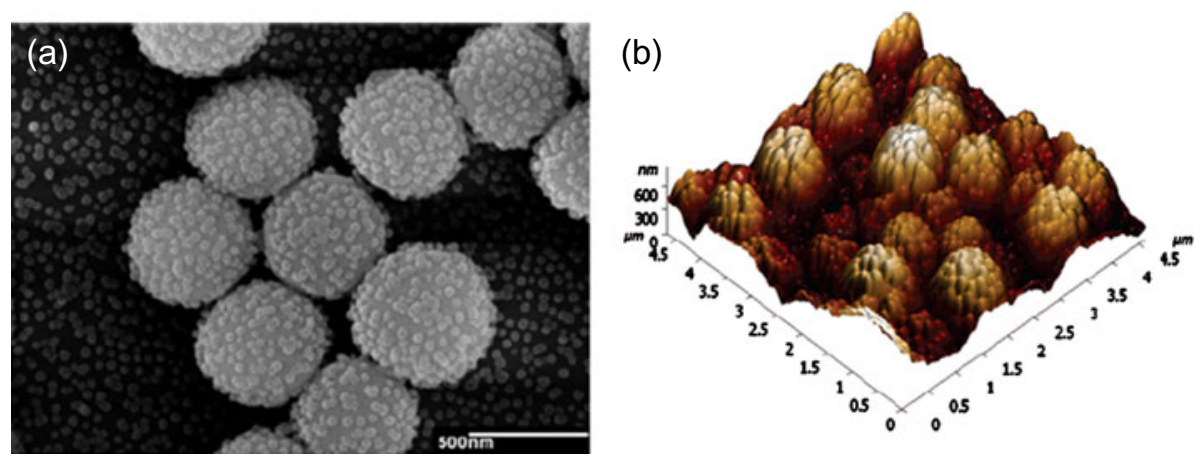

Fig. 10. Biomimetic superhydrophobic surfaces created artificially (a) SEM image of raspberry-like microstructure [77] and (b) 3D AFM image of raspberry-like microstructure created by PDMS covered with epoxy based film [76] (reproduced with permission from Ref. [76,77]).
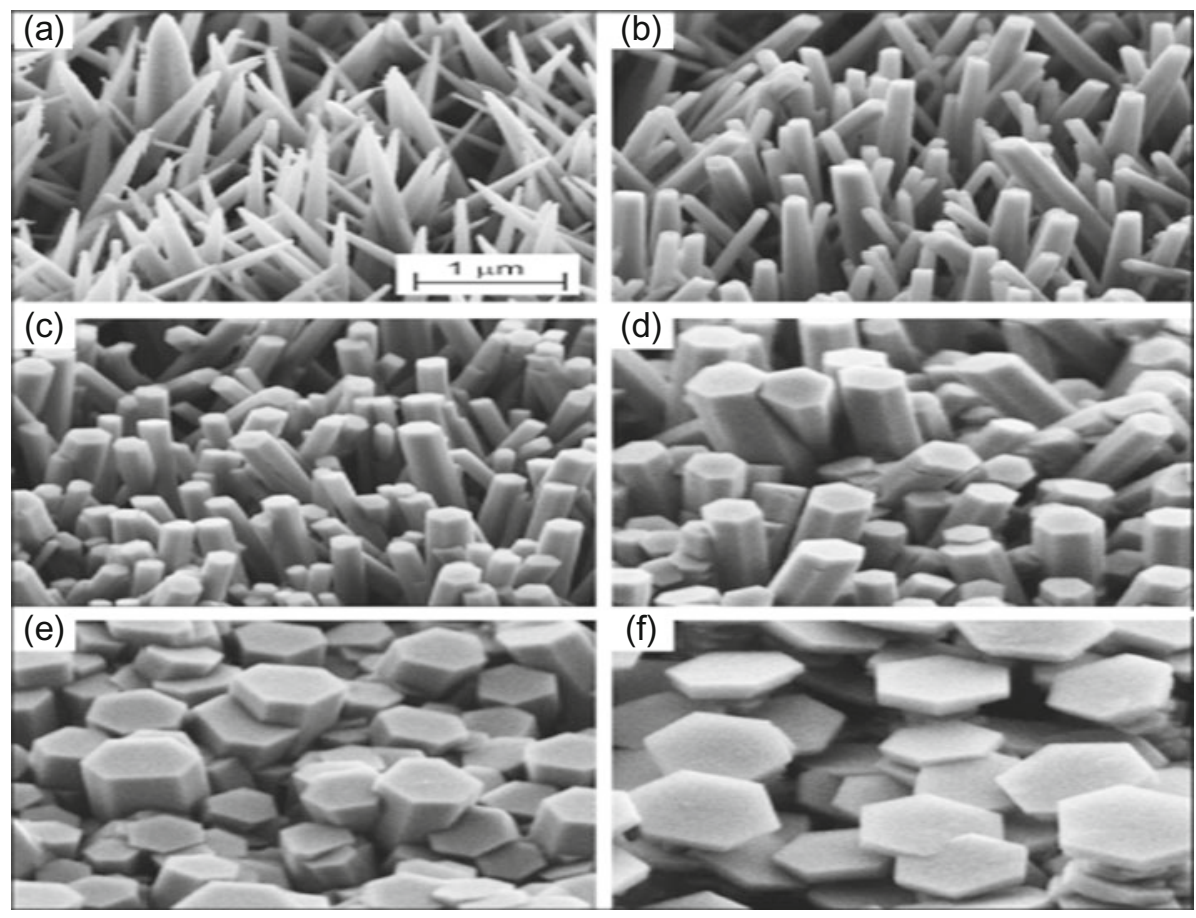

Fig. 11. (a)-(f) Morphology and wetting behavior of oriented $\mathrm{ZnO}$ films grown hydrothermally from nanoparticle-seeded glass substrates (reproduced with permission from Ref. [98]).

nanowire thin film on glass and quartz substrates by thermal oxidation of the metallic Zn film was demonstrated by Shaik et al. [99]. Metal oxide nanoparticles with two different length scales also can produce hierarchical nanostructure with extreme water repellence [100]. In this situation, smaller particles are decorated over larger particle to obtain desired hydrophobicity. It is possible to develop superhydrophobic surfaces from textured surfaces coated with hydrophobic functional groups. SEM images of superhydrophobic nanostructured zinc oxide thin films with different levels of roughness are shown in Figure 11 and example of an artificially engineered superhydrophobic surface is shown in Figure 12.

It is evident from these studies that "designer" structures do not rely only on oxides for exploiting the super- hydrophobic behavior. Therefore, there is a great deal of promise in such periodic structures for the future.

\section{Synthesis and fabrication}

Metal oxide thin films for self-cleaning applications can be deposited by a wide variety of techniques such as sol-gel, spray pyrolysis, liquid phase deposition, physical vapor deposition Chemical deposition, hydrothermal methods [101-119]. In physical and chemical vapour deposition techniques many parameters like pressure, substrate temperature, power density, gas flow rates are available to control properties of films. However, these are not suitable for deposition on flexible substrates. 
(a)

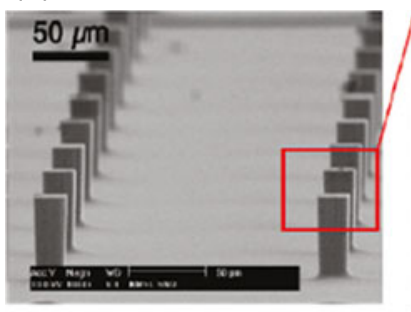

(b)

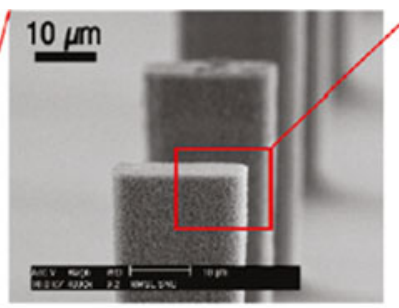

(c)

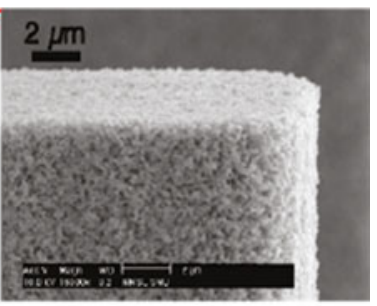

(d)

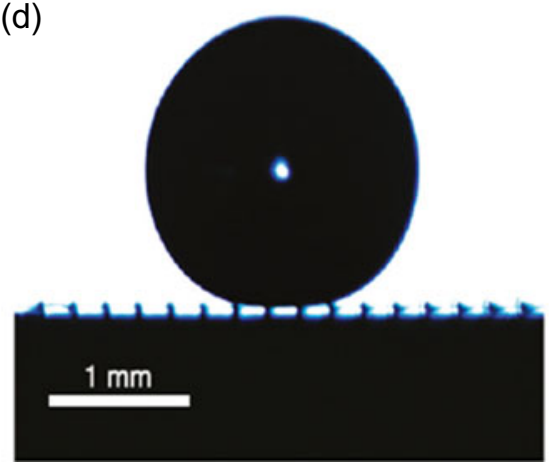

(e)

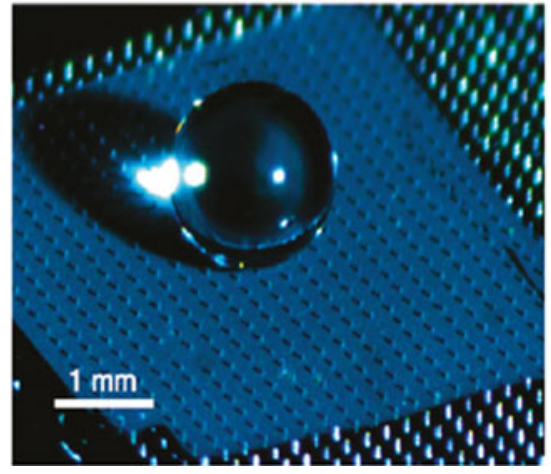

Fig. 12. Example of artificially engineered superhydrophobic surface. Droplet on the fabricated nano-microroughened hierarchical surface. (a)-(c) Nanoscale roughness etched by XeF2 gas that conformally covers the microscale array of pillars fabricated through deep reactive etching. (d) and (e) Droplet sitting on the double roughness supported by only several pillars (reproduced with permission from Ref. [21]).

Non-vacuum techniques that include sol-gel, spray pyrolysis and liquid phase deposition are particularly attractive for commercial purposes because of their low cost, time saving and suitability for large-area coatings. Inkjet printing is a technique that is rapidly emerging as a candidate for the deposition of functional materials on flexible substrates. Inkjet printing of functional materials provides many tunable parameters such as rheology of the inks for a given material, accuracy of patterning, three dimensional overlay accuracy, stitching accuracy of patterns, etc. The challenges that remain are improved uniformity over large areas, deposition of the layers on flexible substrates, morphology, and structure and microstructure optimization $[120,121]$.

Based on the review of literature it can be summarized that low-cost solution-based techniques are emerging as the candidates for large-area self-cleaning applications.

\section{Conclusions and outlook}

A review of self-cleaning surfaces produced by metal oxides, polymeric compounds and metal oxide-polymer nanocomposites is presented. A synthetic procedure concerning nanocomposites of oxides with other inorganic and organic materials and their effect on self-cleaning applications has been discussed. The self-cleaning mechanisms of metal oxide thin films were related to crystal structure, chemical composition and surface morphology. Doping of metal/nonmetal on metal oxide is particularly important because it has the capability of not only narrowing band gap but also prevents electron-hole recombination. Despite the large number of studies on self-cleaning surfaces, the effect of substrate properties on the self-cleaning action is relatively limited. There are challenges for the future progress of these types of materials. It is necessary to retain the superhydrophilicity for a prolonged period of time even under dark storage. The current problem of selfcleaning surfaces is that after a few cycles, self-cleaning properties tend to decay especially in submerged systems and systems exposed to open air. So, future work should focus on achieving self-cleaning films with long-term stability. Though many researchers have studied self-cleaning properties, there are still significant issues that need to be addressed in order to make the technology more feasible. In this context, robustness of the film surface is of vital concern, and it has to be studied in greater detail. There are quite a few investigations on the photocatalytic properties of single layer films, however new schemes such as use of a buffer layer between substrate and metal oxide and artificially engineered surfaces with hierarchical roughness are emerging as the self-cleaning surfaces of the future. This is mainly because the engineered surfaces could be made of either metal or metal oxide, thus expanding the materials horizon for self-cleaning applications. Last but not the least, although there are several ways of depositing a self-cleaning thin film but adherence of the film to the substrate is a major issue, and further insight is required in this area. 


\section{References}

1. W. Barthlott, C. Neinhuis, Planta 202, 1 (1997)

2. X. Zhang, F. Shi, J. Niu, Y. Jiang, Z. Wang, J. Mater. Chem. 18, 621 (2008)

3. Z. Guo, W. Liu, Plant. Sci. 172, 1103 (2007)

4. K. Koch, W. Barthlott, Phil. Trans. R. Soc. A 367, 1487 (2009)

5. Y. Su, B. Ji, Y. Huang, K. Hwang, Langmuir 26, 18926 (2010)

6. D. Byun, J. Hong, Saputra, J.H. Ko, Y.J. Lee, H.C. Park, B. Byun, J.R. Lukes, J. Bionic Eng. 6, 63 (2009)

7. M. Sun, G.S. Watson, Y. Zheng, J.A. Watson, A. Liang, J. Exp. Biol. 212, 3148 (2009)

8. A.R. Parker, C.R. Lawrence, Nature 414, 33 (2001)

9. B. Bhushan, Phil. Trans. R. Soc. A 367, 1445 (2009)

10. K. Liu, L. Jiang, Annu. Rev. Mater. Res. 42, 231 (2012)

11. A. Folli, C. Pade, T.B. Hansen, T.D. Marco, D.E. Macphee, Cem. Concr. Res. 42, 539 (2012)

12. J. Chen, C. Poon, Build. Environ. 44, 1899 (2009)

13. G. Helsch, J. Deubener, Sol. Energy 86, 831 (2012)

14. L.K. Verma, M. Sakhuja, J. Son, A.J. Danner, H. Yang, H.C. Zeng, C.S. Bhatia, Renew. Energy 36, 2489 (2011)

15. P. Eiamchai, P. Chindaudom, M. Horprathum, V. Patthanasettakul, P. Limsuwan, Mater. Eng. 30, 3428 (2009)

16. T. Young, Phil. Trans. R. Soc. Lond. 95, 65 (1805)

17. R. Wenzel, Ind. Eng. Chem. 28, 988 (1936)

18. A.B.D. Cassie, S. Baxter, Trans. Faraday Soc. 40, 546 (1944)

19. E. Bormashenko, Phil. Trans. R. Soc. A 368, 4695 (2010)

20. M. Nosonovsky, B. Bhushan, Ultramicros. 107, 969 (2007)

21. Y. Kwon, N. Patankar, J. Choi, J. Lee, Langmuir 25, $6129(2009)$

22. Y. Lee, Y. Yoo, J. Kim, S. Widhiarini, B. Park, H.C. Park, K.J. Yoon, D. Byun, J. Bionic Eng. 6, 365 (2009)

23. B. Bhushan, Langmuir 28, 1698 (2012)

24. B. Bhushan, Y.C. Jung, Prog. Mater. Sci. 56, 1 (2011)

25. J. Lu, K. Huang, X. Chen, J. Zhu, F. Meng, X. Song, Z. Sun, Appl. Surf. Sci. 257, 2086 (2011)

26. D. Barreca, A. Gasparotto, C. Maccato, E. Tondello, U.L. Stangar, S.R. Patil, Surf. Coat. Technol. 203, 2041 (2009)

27. M. Miyauchi, A. Nakajima, T. Watanabe, K. Hashimoto, Chem. Mater. 14, 2812 (2002)

28. V. Rico, C. Lopez, A. Borras, J.P. Espinos, A.R. Gonzalez-Elipe, Sol. Energy Mater. Sol. Cells 90, 2944 (2006)

29. L. Chen, S. Zhang, L. Wang, D. Xue, S. Yin, J. Cryst. Growth 311, 735 (2009)

30. S. Wang, X. Feng, J. Yao, L. Jiang, Ang. Chem. Int. Ed. 45, $1264(2006)$

31. H. Lim, D. Kwak, D. Lee, S.G. Lee, K. Cho, J. Am. Chem. Soc. 129, 4128 (2007)

32. A. Fujishima, X. Zhang, D.A. Tryk, Surf. Sci. Rep. 63, $515(2008)$

33. X. Zhao, K. Sakka, N. Kihara, Y. Takata, M. Arita, M. Masuda, Curr. App. Phys. 6, 931 (2006)

34. G. Kwak, J. Phys. Chem. C 113, 12085 (2009)

35. M. Guo, Thin Solid Films 515, 7162 (2007)
36. H.C. Barshilia, K.R.S. Tej, L.M. Devi, K.S. Rajam, J. Appl. Phys. 108, 074315 (2010)

37. X. Feng, L. Feng, M. Jin, J. Zhai, L. Jiang, D. Zhu, J. Am. Chem. Soc. 126, 62 (2004)

38. P. Yang, K. Wang, Z. Liang, W. Mai, C. Wang, W. Xie, P. Liu, L. Zhang, X. Cai, S. Tan, J. Song, Nanoscale 4, 5755 (2012)

39. K. Weng, Y. Huang, Surf. Coat. Technol. (in press), DOI: $10.1016 /$ j.surf coat. 2012.06.058

40. K. Qi, B. Fei, J.H. Xin, Thin Solid Films 519, 2438 (2011)

41. A. Eshaghi, A. Eshaghi, Thin Solid Films 520, 1053 (2011)

42. Q. Xu, D.V. Wellia, M. Alam Sk, K.H. Lim, J.S.C. Loo, D.W. Liao, R. Amal, T. Thatt, Y. Tan, J. Photochem. Photobiol. A Chem. 210, 181 (2010)

43. A. Borras, C. Lopez, V. Rico, F. Gracia, A.R. Gonzalez-Elipe, E. Richter, G. Battiston, R. Gerbasi, N. McSporran, G. Sauthier, E. Gyorgy, A. Figueras, J. Phys. Chem. C 111, 1801 (2007)

44. P. Romero-Gomez, V. Rico, A. Borras, A. Barranco, J.P. Espinos, J. Cotrino, A.R. Gonzalez-Elipe, J. Phys. Chem. C 113, 13341 (2009)

45. O. Kesmez, H.E. Camurlu, E. Burunkaya, E. Arpac, Sol. Energy Mater. Sol. Cells 93, 1833 (2009)

46. M. Houmard, D. Riassetto, F. Roussel, A. Bourgeois, G. Berthome, J.C. Joud, M. Langlet, Surf. Sci. 602, 3364 (2008)

47. M. Houmard, D. Riassetto, F. Roussel, A. Bourgeois, G. Berthome, J.C. Joud, M. Langlet, Appl. Surf. Sci. 254, 1405 (2007)

48. D. Wu, M. Long, J. Zhou, W. Cai, X. Zhu, C. Chen, Y. Wu, Surf. Coat. Technol. 203, 3728 (2009)

49. M. Montazer, E. Pakdel, J. Text. Inst. 102, 343 (2011)

50. N. Veronovski, A. Rudolf, M.S. Smole, T. Kreze, J. Gersak, Fiber. Polym. 10, 551 (2009)

51. N.M. Bedford, A.J. Steckl, ACS Appl. Mater. Int. 2, 2448 (2010)

52. R. Asmatulu, M. Ceylan, N. Nuraje, Langmuir 27, 504 (2011)

53. M.J. Uddin, F. Cesano, D. Scarano, F. Bonino, G. Agostini, G. Spoto, S. Bordiga, A. Zecchina, J. Photochem. Photobiol. A Chem. 199, 64 (2008)

54. G. Li, H. Liu, H. Zhao, Y. Gao, J. Wang, H. Jiang, R.I. Boughton, J. Coll. Interf. Sci. 358, 307 (2011)

55. H. Moafi, A. Shojaie, M. Zanjanchi, Appl. Surf. Sci. 256, $4310(2010)$

56. K. Qi, X. Chen, Y. Liu, J.H. Xin, C.L. Mak, W.A. Daoud, J. Mater. Chem. 17, 3504 (2007)

57. W.S. Tung, W.A. Daoud, J. Coll. Interf. Sci. 326, 283 (2008)

58. W.S. Tung, W.A. Daoud, J. Appl. Polym. Sci. 112, 235 (2009)

59. G.K. Hyde, G. Scarel, J.C. Spagnola, Q. Peng, K. Lee, B. Gong, K.G. Roberts, K.M. Roth, C.A. Hanson, C.K. Devine, S.M. Stewart, D. Hojo, J.S. Na, J.S. Jur, G.N. Parsons, Langmuir 26, 2550 (2010)

60. N. Vigneshwaran, S. Kumar, A.A. Kathe, P.V. Varadarajan, Nanotechnol. 17, 5087 (2006)

61. Ş.S. Ugur, M. Sarışık, A.H. Aktaş, M.C. Uçar, E. Erden, Nano. Res. Lett. 5, 1024 (2010) 
62. B. Xu, Z. Cai, F. Ge, Surf. Coat. Technol. 204, 1556 (2010)

63. V.S. Gowri, L. Almeida, M.T.P. Amorim, N.C. Pacheco, A.P. Souto, M.F. Esteves, S.K. Sanghi, J. Mater. Sci. 45, $2427(2010)$

64. A.C. Popescu, L. Duta, G. Dorcioman, I.N. Mihailescu, J. Appl. Phys. 110, 064321 (2011)

65. Z. Liu, X. Zhang, T. Murakami, A. Fujishima, Sol. Energy Mater. Sol. Cells 92, 1434 (2008)

66. R. Prado, G. Beobide, A. Marcaide, J. Goikoetxea, A. Aranzabe, Sol. Energy Mater. Sol. Cells 94, 1081 (2010)

67. E. Quagliarini, F. Bondioli, G.B. Goffredo, C. Cordoni, P. Munafo, Constr. Build. Mater. 37, 51 (2012)

68. E. Quagliarini, F. Bondioli, G.B. Goffredo, A. Licciulli, P. Munafo, J. Cultur. Herit. 13, 204 (2012)

69. M. Hadnadjev, J. Ranogajec, S. Petrovic, S. Markov, V. Ducman, R. Marinkovic-Neducin, J. Phil. Mag. 90, 2989 (2010)

70. X. Ding, S. Zhou, L. Wu, G. Gu, J. Yang, Surf. Coat. Technol. 205, 2554 (2010)

71. K. Nakata, H. Kimura, M. Sakai, T. Ochiai, H. Sakai, T. Murakami, M. Abe, A. Fujishima, ACS Appl. Mater. Int. 2, 2485 (2010)

72. C. Su, Appl. Surf. Sci. 256, 2122 (2010)

73. W. Hou, Q. Wang, Langmuir 25, 6875 (2009)

74. P.N. Manoudis, I. Karapanagiotis, A. Tsakalof, I. Zuburtikudis, C. Panayiotou, Langmuir 24, 11225 (2008)

75. J. Kasanen, M. Suvanto, T.T. Pakkanen, J. Appl. Polym. Sci. 111, 2597 (2009)

76. W. Ming, D. Wu, R. van Benthem, G. de With, Nano Lett. 5, 2298 (2005)

77. H. Tsai, Y. Lee, Langmuir 23, 12687 (2007)

78. J. Xiong, S. Das, B. Shin, J. Kar, J.H. Choi, J. Myoung, J. Coll. Interf. Sci. 350, 344 (2010)

79. P. Roach, N.J. Shirtcliffe, M.I. Newton, Soft Matt. 4, 224 (2008)

80. H.K. Park, S.W. Yoon, Y.R. Do, J. Mater. Chem. 22, 14035 (2012)

81. K.K.S. Lau, J. Bico, K.B.K. Teo, M. Chhowalla, G.A.J. Amaratunga, W.I. Milne, G.H. McKinley, K.K. Gleason, Nano Lett. 3, 1701 (2003)

82. J. Yang, P. Pi, X. Wen, D. Zheng, M. Xu, J. Cheng, Z. Yang, Appl. Surf. Sci. 255, 3507 (2009)

83. T. Ogawa, B.Y. Sone, S. Shiratori, Nanotechnol. 18, 165607 (2007)

84. X. Liu, J. He, Langmuir 25, 11822 (2009)

85. D.M. Chun, M.H. Kim, J.C. Lee, S.H. Ahn, CIRP Ann. 57, 551 (2008)

86. C.R. Crick, I.P. Parkin, Ind. Eng. Chem. Res. 47, 6354 (2008)

87. Z. Yuan, J. Xiao, J. Zeng, C. Wang, J. Liu, S. Xing, D. Jiang, G. Du, F. Yang, C. Peng, H. Chen, Q. Ye, J. Tang, Surf. Coat. Technol. 205, 1947 (2010)

88. Y. Park, H. Im, M. Im, Y. Choi, J. Mater. Chem. 21, 633 (2011)

89. N.J. Shirtcliffe, G. McHale, M.I. Newton, J. Polym. Sci. B 49, 1203 (2011)

90. A. Synytska, L. Ionov, K. Grundke, M. Stamm, Langmuir 25, $3132(2009)$
91. A. Milella, R. Mundo, F. Palumbo, P. Favia, F. Fracassi, R. Agostino, Plasma Processes Polym. 6, 460 (2009)

92. M.A. Nilsson, R.J. Daniello, J.P. Rothstein, J. Phys. D. 43, $045301(2010)$

93. Z. Guo, X. Chen, J. Li, J. Liu, X. Huang, Langmuir 27, $6193(2011)$

94. J. Wu, J. Xia, W. Lei, B. Wang, Mater. Lett. 64, 1251 (2010)

95. W. Zhu, X. Feng, L. Feng, L. Jiang, Chem. Commun. $2753(2006)$

96. J. Wu, J. Xia, C. Jing, W. Lei, B. Wang, Appl. Phys. A 105, 221 (2011)

97. A. Chen, X. Peng, K. Koczkur, B. Miller, Chem. Commun. 1964 (2004)

98. M. Piech, T.L. Sounart, J. Liu, J. Phys. Chem. C 112, 20398 (2008)

99. U.P. Shaik, S. Kshirsagar, M.G. Krishna, S.P. Tewari, D.D. Purkayastha, V. Madhurima, Mater. Lett. 75, 51 (2012)

100. B. Hipp, I. Kunert, M. Deurr, Langmuir 26, 6557 (2010)

101. M. Faustini, L. Nicole, C. Boissiere, P. Innocenzi, C. Sanchez, D. Grosso, Chem. Mater. 22, 4406 (2010)

102. M. Langlet, S. Permpoon, D. Riassetto, G. Berthome, E. Pernot, J.C. Joud, J. Photochem. Photobiol. A Chem. 181, 203 (2006)

103. A.I. Kontos, A.G. Kontos, D.S. Tsoukleris, G.D. Vlachos, P. Falaras, Thin Solid Films, 515, 7370 (2007)

104. M. Kazemia, M.R. Mohammadizadeh, Appl. Surf. Sci. 257, $3780(2011)$

105. N.L. Tarwal, V.M. Khot, N.S. Harale, S.A. Pawar, S.B. Pawar, V.B. Patil, P.S. Patil, Surf. Coat. Technol. 206, 1336 (2011)

106. G. Socol, Yu. Gnatyuk, N. Stefan, N. Smirnova, V. Djokic, C. Sutan, V. Malinovschi, A. Stanculescu, O. Korduban, I.N. Mihailescu, Thin Solid Films 518, 4648 (2010)

107. C. Hsieh, M. Lai, Y. Cheng, J. Coll. Interf. Sci. 340, 237 (2009)

108. J. Xiong, S. Das, S. Kim, J. Lim, H. Choi, J. Myoung, Surf. Coat. Technol. 204, 3436 (2010)

109. T. Tolke, A. Kriltz, A. Rechtenbach, Thin Solid Films 518, 4242 (2010)

110. D. Vernardou, G. Kalogerakis, E. Stratakis, G. Kenanakis, E. Koudoumas, N. Katsarakis, Solid State Sci. 11, 1499 (2009)

111. Z. Lu, X. Jiang, B. Zhou, X. Wu, L. Lu, Appl. Surf. Sci. 257, 10715 (2011)

112. B.A. Nejand, S. Sanjabi, V. Ahmadi, Vacuum 85, 400 (2010)

113. C. Euvananont, C. Junin, K. Inpor, P. Limthongkul, C. Thanachayanont, Ceram. Int. 34, 1067 (2008)

114. M.E. Simonsen, Z. Li, E.G. Sogaard, Appl. Surf. Sci. 255, 8054 (2009)

115. S. Karuppuchamy, J. Jeong, Mater. Chem. Phys. 93, 251 (2005)

116. L. Zhao, M. Han, J. Lian, Thin Solid Films 516, 3394 (2008)

117. B.S. Boroujeny, A. Afshar, A. Dolati, Thin Solid Films 520, 6355 (2012) 
118. Q. Mu, Y. Li, H. Wang, Q. Zhang, J. Coll. Interf. Sci. 365, 308 (2012)

119. K. Katsumata, A. Nakajima, H. Yoshikawa, T. Shiota, N. Yoshida, T. Watanabe, Y. Kameshima, K. Okada, Surf. Sci. 579, 123 (2005)

120. S.H. Ko, D. Lee, N. Hotz, J. Yeo, S. Hong, K.H. Nam, C.P. Grigoropoulos, Langmuir 28, 4787 (2012)

121. M. Arin, P. Lommensa, N. Avci, S.C. Hopkins, K. Buysser, I.M. Arabatzis, I. Fasaki, D. Poelman, I.V. Driessche, J. Eur. Ceram. Soc. 31, 1067 (2011)
Open Access This article is distributed under the terms of the Creative Commons Attribution License http:// creativecommons.org/licenses/by/2.0 which permits unrestricted use, distribution, and reproduction in any medium, provided the original author(s) and source are credited.

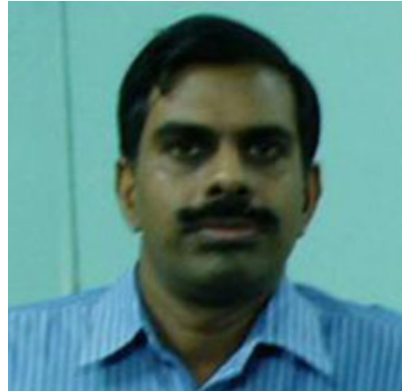

M. Ghanashyam Krishna

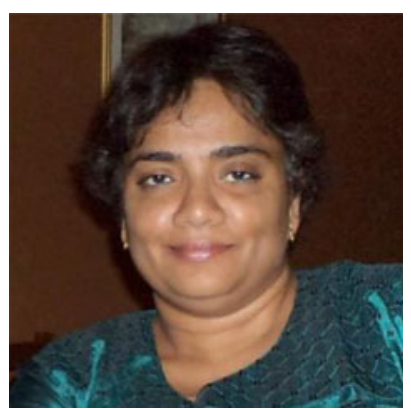

V. Madhurima

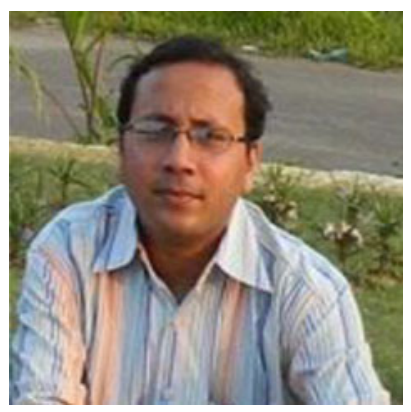

Debarun Dhar Purkayastha
M. Ghanashyam Krishna obtained his B.Sc.(Hons.) degree in 1984 and M.Sc. Physics degree in 1986 from Delhi University, India. He received a PhD from the Indian Institute of Science, Bengaluru, India in 1992 for thesis work on lon assisted deposition of oxide thin films. After a five year post doctoral stint at the University of Warwick, UK, Ghanashyam Krishna joined the faculty of School of Physics, University of Hyderabad in 2001, where he is currently a Professor. Ghanashyam Krishna's research interests include functional nanostructured thin films and development of non-lithographic techniques for nanostructuring of thin films. He has over 100 research papers and is currently Associate editor of Bulletin of Materials Science.

V. Madhurima obtained her Bachelor of Science degree from Madras University in 1991, Master of Science in Physics (1993) followed by a PhD (1999) in Physics from Indian Institute of Technology, Madras, India. She went on to do post-doctoral research work at the School of Physics, University of Hyderabad, between 2004 and 2007. Her research interests include study of intermolecular interactions in liquids and soft materials and their applications. She is presently an Associate Professor at Central University of Tamil Nadu, Thiruvarur, India where she moved from Mizoram University, Aizawl, in 2012.

Debarun Dhar Purkayastha obtained his PhD in Physics from Mizoram University in 2013 under the supervision of Dr. V. Madhurima. He received his B.Sc (2005) and M.Sc (2007) degree in Physics from Assam University. He is currently a postdoctoral fellow under Prof. M. Ghanashyam Krishna at School of Physics, University of Hyderabad. His current research interests include metal oxide, doped metal oxide, Polymer-metal oxide based thin films for self cleaning applications. 